\title{
Hypoglycemic and Hypolipidemic Activities of Bile of Bangladeshi Labeo rohita on Streptozotocin (STZ) - Induced Diabetic Rats
}

\author{
Ridoy Ahamed ${ }^{1}$, Afifa Parvin Shanta ${ }^{1}$, Israt Jahan Bulbul ${ }^{1}$, Md. Mahbubur Rahman \\ Tanim ${ }^{1}$, Md. Ruhul Kuddus ${ }^{2}$ and Mohammad A. Rashid ${ }^{2}$ \\ ${ }^{1}$ Department of Pharmacy, Southeast University, Banani, Dhaka-1213, Bangladesh \\ ${ }^{2}$ Phytochemical Research Laboratory, Department of Pharmaceutical Chemistry, Faculty of Pharmacy \\ University of Dhaka, Dhaka-1000, Bangladesh
}

(Received: November 5, 2021; Accepted: January 22, 2022; Published (web): January 29, 2022)

\begin{abstract}
Diabetes mellitus (DM) is one of the most commonly diagnosed condition all over the world. Fish is a typical delicacy and one of the most nutritious foods available. Fresh fish bile, according to various indigenous healthcare professionals in Bangladesh, has anti-diabetic effects and its importance in the treatment or management of diabetes and cardiovascular illnesses has also been documented in few recent studies. The goal of this work was to test the hypoglycemic potential of Labeo rohita bile content in order to objectively validate this folklore claim. In this study, in-vivo investigation of the hypoglycemic and hypolipidemic activities of $L$. rohita bile was performed against a streptozotocininduced diabetic rat model. Rats were given bile extract at doses of $0.08 \mathrm{ml} / \mathrm{kg}$ body weight and 0.16 $\mathrm{ml} / \mathrm{kg}$ body weight for one week. Here, metformin $\mathrm{HCl}(100 \mathrm{mg} / \mathrm{kg}$ body weight $)$ was used as reference standard. Both the doses of bile extract exhibited significant hypoglycemic effect $(\mathrm{p}<0.05)$ compared to control as well as untreated diabetic control rats. Total cholesterol (TC), triglyceride (TG), low density lipoprotein cholesterol (LDL-C) and high-density lipoprotein cholesterol (HDL-C) levels were also investigated from blood samples followed by 7 days of therapy. The results revealed that both doses of L. rohita bile bear a significant hypolipidemic effect. This study could be beneficial in diabetic and hyperlipidemia conditions.
\end{abstract}

Key words: Labeo rohita, metformin $\mathrm{HCl}$, streptozotocin, hypoglycemic, hypolipidemic, rats.

\section{Introduction}

Diabetes mellitus is a metabolic condition defined by an increase in blood glucose levels due to a lack of insulin release or impaired insulin activity, or sometimes both (Mitra, 2008). Diabetes mellitus is a primary health issue worldwide affecting 382 million people, while responsible for 5.3 million deaths per year (Han Cho, 2014; Danaei et al., 2011). This numbers are predicted to rise approximately 592 million over the world within 2035 (Mendis et al., 2011; Guariguata et al., 2014). Diabetes is the $7^{\text {th }}$ distinguishable risk factor among burden of disease in south Asian nations (Lim et al., 2012).
In Bangladesh, current meta-analysis observed that the prevalence in male and female adults had risen to 149.8 million people in 2011. The number of impacted people had gradually increased from 1995 to 2010 (Saquib et al., 2012). Based on the International Diabetes Federation (IDF), the prevalence will be increasing to around $13 \%$ by 2030 (International Diabetes Federation $6^{\text {th }}$ edition, 2012).

Lipid dysfunction is defined to have a high or low blood lipid level, which is considered as a significant risk element for atherosclerosis progression. Hypertension and dyslipidemia are key

Corresponding author: Mohammad A. Rashid; E-mail: r.pchem@yahoo.com DOI: https://doi.org/10.3329/bpj.v25i1.57838 
risk factors for cardiovascular disease, with the Bangladeshi population suffering from the highest rates of morbidity and mortality (Choudhury et al., 2014).

Most of our rural people are poor; they can't afford costly synthetic drugs and depend on cheap and effective natural sources for the treatment of diabetes. Traditional remedy is an alternate way for treating diabetes because of its perceptions, tolerability, and it has less adverse effects in clinical trials and is reasonably inexpensive.

Insulin and several oral hypoglycemic medications are now accessible treatments for diabetes, but they have been linked to major side effects such as liver problems, lactic acidosis, and other complications. Besides, various types of alternative medicines also possess anti-diabetic properties and are used to treat diabetes and most of the people are very much interested in those types of medicines for their treatment rather than synthetic medicine.

Liver of most vertebrates produces bile or gall, which assists in the breakdown of lipids when secreted in the small intestine. Bile is a crucial aspect for absorbing fat-soluble components, such as vitamin $\mathrm{A}, \mathrm{D}, \mathrm{E}$ and $\mathrm{K}$. Bile salts also work as bactericides, killing a wide range of microorganisms that may be found in foodstuffs. Bile alcohol, bile acids, sterols, phenolics, and traces of steroidal hormones make up L. rohita bile (Hofmann et al., 2010).

A few traditional medical practitioners in India's tribal groups (locally known as auchai or kabiraj) stated that other elements of the fish, such as bile from fresh water fish, had therapeutic effects in diabetes. They prepare it by cooking with chilies and onions (Deb et al., 2012). There are few reported data on fish bile that it is capable of managing hyperglycemia, hyperlipidemia and associated complications in diabetes (Ahmad et al., 2017).

As our country is called land of rivers and different varieties of fishes are very much available in Bangladesh. Keeping this in view, the present research was conducted to assess the hypoglycemic and hypolipidemic actions of the bile of the Bangladeshi L. rohita fish.

\section{Materials and Methods}

Collection of $L$. rohita and preparation of bile solution: Bile was collected from the gall bladder of L. rohita. Bile extract was liquid and water soluble. The dosage was made in a water-based solution. The required amount of bile extract was calculated in order to deliver the bile extract with the doses amount of $0.08 \mathrm{ml} / \mathrm{kg} \mathrm{b}$.w. and $0.16 \mathrm{ml} / \mathrm{kg} \mathrm{b.w}$. of rats. The diabetic and non-diabetic control groups of animals were given drinking water. For 7 days, all rats were kept in the above-mentioned experimental conditions.

Chemicals and reagents: Metformin $\mathrm{HCl}$ and streptozotocin (STZ) were purchased from Chadwell Health Essex, England. Wet reagent diagnostic kits were used to analyze plasma triglycerides, total cholesterol, low density lipoprotein cholesterol and high-density lipoprotein cholesterol concentrations (Linear Chemicals, Spain). Both the blood glucose test strip and glucose monitoring system were collected from Tyson Bioresearch, Based Industrial Park, Chu-Nan, Taiwan. The fish (L. rohita) weighing between 1-2 Kg were obtained from a local fish market at Karwan Bazar, Dhaka-1215, Bangladesh.

Animals: Adult Long Evan Rats (body weight range 120-140 g), 8-9 weeks of age were purchased from ICDDR, B. Animals were housed in cages, which were available with enough food and water under regular surroundings (humidity 40-60\%, 22$25^{\circ} \mathrm{C}, 12 \mathrm{~h}$ dark: $12 \mathrm{~h}$ light rotation). Animals were accommodated in standard cages with continuous food supply in a well-ventilated room. These activities were performed in compliance with the animal experimental guidelines of our organization.

Induction of diabetes: To develop diabetes, a single dose of $70 \mathrm{mg} / \mathrm{kg}$ STZ was administered by intraperitoneal injection immediately after preparation in distilled water. Before that, the animals were fasted for overnight. The animals in the control group were given 0.9 percent sterile saline. Blood glucose level in the vein of rat tail was checked with 
a glucose monitoring equipment three days after injection, hyperglycemia was confirmed (Match 2, originated from China). The rats chosen for the study had a blood glucose level of greater than $7 \mathrm{mmol} / \mathrm{l}$.

Experimental design: To find out the hypoglycemic activity, rats were allocated into five groups randomly as I-V, each group consists of four rats, all of which received a one-week medication except the normal control group, for determining the blood glucose and lipid profile. Group I was termed as control group (Non diabetic); group II was named as untreated diabetic control group; group III was treated with metformin $\mathrm{HCl}$ at a dose of 100 $\mathrm{mg} / \mathrm{kg}$ b.w.; group IV with $0.08 \mathrm{ml} / \mathrm{kg}$ b.w. bile extract and group $\mathrm{V}$ was treated with $0.16 \mathrm{ml} / \mathrm{kg}$ b.w. bile extract.

Diabetes was generated via intraperitoneal injection of streptozotocin to groups II to V. Regular food and water were provided to group I. Group II was given streptozotocin $(70 \mathrm{mg} / \mathrm{kg})$ using normal saline water subcutaneously and this group was utilized as diabetic control. Group III was given metformin $\mathrm{HCl}$ throughout 7 days, and group IV-V were given the test medication of bile over 7 days orally. Then blood glucose level was measured after 3 days, 5 days and 7 days of the treatment period with the standard and test drugs. The percentage inhibition of blood glucose level was calculated from the formula:

$$
\left.(\% \text { Inhibition })=\frac{\mathrm{B}_{\mathrm{O}}-\mathrm{B}_{\mathrm{T}}}{\mathrm{B}_{\mathrm{O}}} \times 100 \%\right)
$$

Where, $\mathrm{B}_{\mathrm{O}}$ : Blood glucose level of diabetic rats without treatment, $\mathrm{B}_{\mathrm{T}}$ : Blood glucose level of treated diabetic rats

Biochemical parameters: Following one week of therapy, blood samples were collected from each rat for further investigation of the lipid profile. Blood was typically withdrawn very slowly from the heart possibly from the ventricle. The plasma portion was frozen at $-4^{\circ} \mathrm{C}$ until biochemical analysis, and the blood sample was centrifuged for $20 \mathrm{~min}$ at 4000 rpm. TC, TG, LDL-C, and HDL-C concentrations were determined colorimetrically using commercially available wet reagent diagnostic kits on a blood analyzer (HUMAN GmbH, Germany).

Statistical analysis: Each of the characteristics was statistically examined utilizing SPSS software. One-way ANOVA was performed for determining the statistical significance between the groups. The results were reported as mean \pm SEM for four animals, with $\mathrm{p}$ values less than 0.05 suggesting statistical significance.

\section{Result and Discussion}

Effect of bile on blood glucose level: Following sequential seven days treatment with bile at two different doses, the effect of bile on blood glucose levels in Long Evan rats is shown in Figure 1. When contrasted the blood glucose level of the control with STZ stimulated rats, there is a considerable increase in blood glucose concentration of all those groups of rats that were given $70 \mathrm{mg} / \mathrm{kg} \mathrm{STZ}$. For non-diabetic rats, the blood glucose concentrations remained constant throughout the study, while for untreated diabetic group the blood glucose level increased significantly. But oral administration of bile extracts $(0.08 \mathrm{ml} / \mathrm{kg} \& 0.16 \mathrm{ml} / \mathrm{kg})$ and metformin $\mathrm{HCl}(100$ $\mathrm{mg} / \mathrm{kg}$ ) to diabetic rats reduced blood glucose concentrations significantly. At the $7^{\text {th }}$ day of treatment, metformin $\mathrm{HCl}$ and bile extracts of 0.08 $\mathrm{ml} / \mathrm{kg}$ and $0.16 \mathrm{ml} / \mathrm{kg}$ reduced blood glucose levels by $65.43 \%, 58.88 \%$ and $63.50 \%$ (Table 1 ). All these values were statistically significant.

\section{Effect of bile on lipid profile}

The effect of the bile on TC, TG, LDL-C and HDL-C in diabetic rats is presented in Figure 2. After 7 days treatment with two different doses of bile as well as standard, the blood samples were tested for the lipid profile. For the treatment groups HDL-C level in blood was increased while TG and LDL-C level in blood were decreased compared to both the control and untreated diabetic groups. The administration of bile extracts $(0.08 \mathrm{ml} / \mathrm{kg} \& 0.16$ $\mathrm{ml} / \mathrm{kg})$ and metformin $\mathrm{HCl}(100 \mathrm{mg} / \mathrm{kg})$ significantly decreased $(\mathrm{p}<0.05)$ the TG and LDL-C, while increased HDL-C level in the blood. 
The percent inhibition for serum TG level was found to be decreased by $36.80 \%$ when treated with $100 \mathrm{mg} / \mathrm{kg}$ of metformin $\mathrm{HCl}$ and $31.60 \%$ and 34.36 $\%$ for the administration of $0.08 \mathrm{ml} / \mathrm{kg}$ and 0.16 $\mathrm{ml} / \mathrm{kg}$ of bile extract, respectively as compared to untreated diabetic rats. The percent inhibition of serum TC levels for $100 \mathrm{mg} / \mathrm{kg}$ of metformin $\mathrm{HCl}$,
$0.08 \mathrm{ml} / \mathrm{kg}$ and $0.16 \mathrm{ml} / \mathrm{kg}$ bile extracts were found as $15.92 \%, 17.71 \%$ and $20.90 \%$, respectively related to untreated diabetic rats. The percent inhibition of serum LDL-C for $0.08 \mathrm{ml} / \mathrm{kg}$ and $0.16 \mathrm{ml} / \mathrm{kg}$ bile extracts were observed as $61.07 \%$ and $84.73 \%$, while for metformin $\mathrm{HCl}$, it was $58.06 \%$ compared to untreated diabetic group rats.

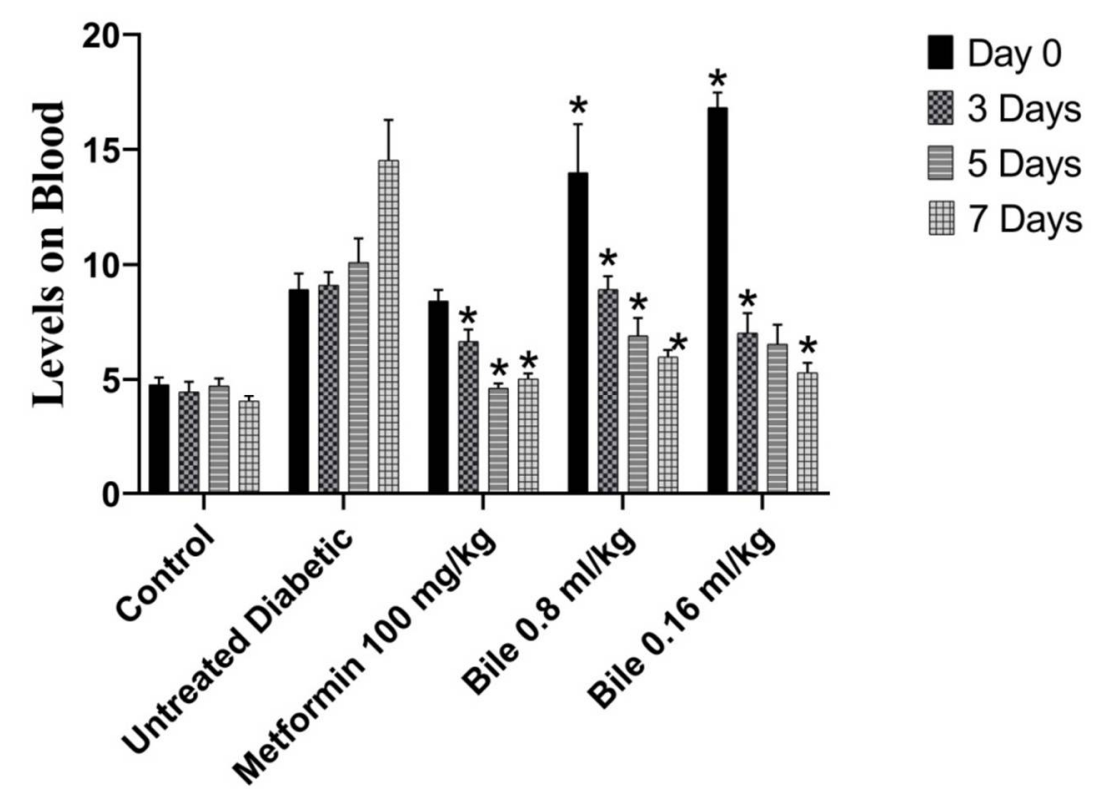

Figure 1. Effect on BDG (blood glucose) level in diabetic rats after bile administration; Data are represented as mean \pm SEM; Animal number per group is $4(n=4)$; the significance of the result was expressed as $* \mathrm{p}<0.05$, where * indicates comparison with control.

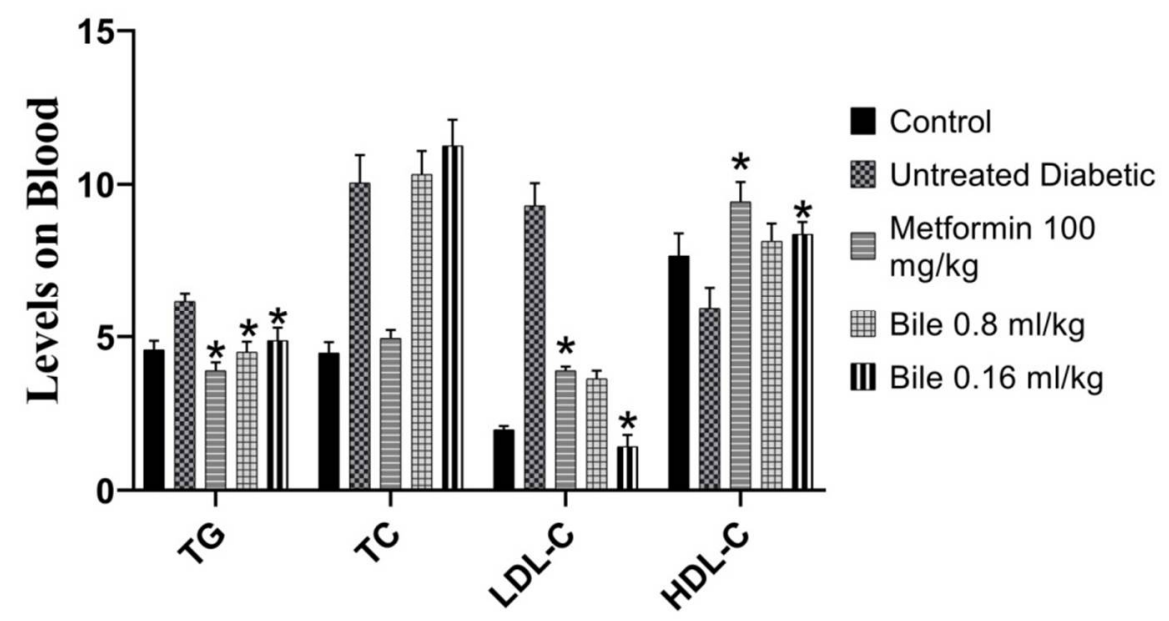

Figure 2. Effect on lipid profile in diabetic rats after bile administration; Data are represented as mean \pm SEM; Animal number per group is $4(n=4)$; the significance of the result was expressed as $* \mathrm{p}<0.05$, where * indicates comparison with control. 
Besides, treatment with metformin $\mathrm{HCl}$ deteriorates the antioxidant defense system's capacity increased $58.31 \%$ serum HDL-whereas bile extracts at both the doses of $0.08 \mathrm{ml} / \mathrm{kg}$ and $0.16 \mathrm{ml} / \mathrm{kg}$ increased $36.97 \%$ and $40.67 \%$, respectively (Table 1). and encourages the formation of new free radicals, which can cause liver cell impairment. In STZtreated rats, there was a significant increase in LPO, resulting in cellular damage and breakdown of the

Hyperglycemia causes a rise in free radical production due to glucose auto-oxidation, which endogenous antioxidant protection systems for avoiding excessive free radical generation.

Table 1. Percent inhibition of blood glucose level and lipid profile in diabetic rats (STZ induced) after treatment with $100 \mathrm{mg} / \mathrm{kg}$ metformin $\mathrm{HCl}, 0.08 \mathrm{ml} / \mathrm{kg}$ and $0.16 \mathrm{ml} / \mathrm{kg}$ bile extract from $L$. rohita.

\begin{tabular}{|c|c|c|c|c|c|c|}
\hline \multirow{2}{*}{ Treatment group } & \multirow{2}{*}{ Doses } & \multicolumn{5}{|c|}{$\%$ Inhibition } \\
\hline & & TG & $\mathrm{TC}$ & LDL-C & HDL-C & BDG \\
\hline Metformin $\mathrm{HCl}$ & $100 \mathrm{mg} / \mathrm{kg}$ & 36.80 & 15.92 & 58.06 & 58.32 & 65.43 \\
\hline Bile_1 & $0.08 \mathrm{ml} / \mathrm{kg}$ & 31.60 & 17.71 & 61.07 & 36.97 & 58.88 \\
\hline Bile_2 & $0.16 \mathrm{ml} / \mathrm{kg}$ & 34.36 & 20.90 & 84.73 & 40.67 & 63.50 \\
\hline
\end{tabular}

Here, $\mathrm{TG}=$ triglyceride, $\mathrm{TC}=$ total cholesterol, LDL-C = low density lipoprotein cholesterol, HDL-C = high density lipoprotein cholesterol, $\mathrm{BDG}=$ blood glucose level.

In diabetic rats, triglyceride (TG), cholesterol, and HDL levels all increased, whereas HDL levels decreased. This could have happened in diabetic rats due to a shortage of insulin, which triggers lipase enzymes, hydrolyzing stored TG and releasing huge quantities of fatty acids and glycerol into the bloodstream. As a result, an increase of fatty acids in the plasma may enhance hepatic transformation of fatty acids to phospholipids and cholesterol, the primary end product of lipid metabolism. Diabetic rats' blood contains higher levels of TG and cholesterol, which could develop into cardiovascular disease. Bile acids help to break down and absorb monoacylglycerols, fatty acids, other fatty products and vitamins (fat-soluble) by acting as potent detergents or emulsifying agents in the intestines. They promote lipolysis by making it easier for pancreatic lipase to adhere to its co-lipase.

Bile acids serve as signaling molecules as well as aiding to absorb dietary lipid substances and maintaining cholesterol homeostasis. These bind with a nucleus receptor (FXR) that controls the expression of several genes associated with triacylglycerol, sterol \& carbohydrate metabolism, and they trigger a particular G-protein-coupled receptor. Such two receptors have varied selective sensitivities for distinct bile acids and their expression patterns relate to different signaling activities in different tissues. Bile acids govern their own production and enterohepatic circulation, as well as lipid and glucose metabolism, through a variety of signaling mechanisms. They control biosynthesis of triacylglycerol and very-low-density lipoproteins (VLDL) generation in liver, reduce triacylglycerol level in plasma. Optimization of the metabolism of bile acid may be a beneficial strategy to manage metabolic disorders as well as type 2 diabetes reported by Prawitt et al. (2011). The possible mechanism by which bile brings about its antihyperglycemic activity may be by increasing the pancreatic secretion of insulin from the existing beta cells or facilitating its release from the bound insulin (Supriya et al., 2010).

In contrast to untreated diabetic rats, fish bile greatly reduced blood glucose levels and boosted HDL-C, while dropping LDL-C, TG, TC level following 7 days of therapy. Metformin $\mathrm{HCl} 100$ $\mathrm{mg} / \mathrm{kg}$ b.w. (40.38 percent) and bile extract 0.08 $\mathrm{ml} / \mathrm{kg} \mathrm{b.w}$. and $0.16 \mathrm{ml} / \mathrm{kg}$ (57.35 percent and 68.48 percent) both reduced blood glucose concentrations. Bile's anti-hyperglycemic function could be due to its potentiating the insulin impact of plasma by 
enhancing either insulin release from prevailing $\beta$ cells of pancreas or its discharge from bound insulin. As a result, it was found to be helpful in reducing diabetes symptoms and optimizing lipid metabolism.

\section{Conclusion}

The bile extract of $L$. rohita was found to have a hypoglycemic effect on STZ-induced diabetic rats in this experiment. The lipid profile of this extract was also improved. This research will pave the road for a natural diabetic treatment that avoids the side effects of manmade medicines. As a result, the L. rohita bile could be studied further for its clinical utility in the treatment of diabetes and its effects. Characterizing the chemicals present in bile that are mainly accountable for their therapeutic benefits, as well as determining their mode of action, will require more research.

\section{References}

Ahmad, D., Pottoo, F.H., Kumar, R.B.S., Haldar, S. and Haldar, P.K. 2017. Rohu fish (Labio rohita) bile attenuates streptozotocin-induced diabetes mellitus in rats: evidence from biochemical and oxidative stress markers. Austin J. Pharmacol. Ther. 5, 1087.

Barrett, Kim E. 2012. Ganong's Review of Medical Physiology $\left(24^{\text {th }}\right.$ ed.). New York: McGraw-Hill Medical. ISBN 978-0-07-178003-2. p 512.

Choudhury, K.N., Mainuddin, A.K.M., Wahiduzzaman, M. and Islam, S.M.S. 2014. Serum lipid profile and its association with hypertension in Bangladesh. Vasc. Health Risk Manag.10, 327-332.

Danaei, G., Finucane, M.M., Lu, Y., Singh, G.M., Cowan, M. J., Paciorek, C. J Singh, G.M., Lin, J.K., Stevens, G.A., Riley, L.M. and Ezzati, M. 2011. Global burden of metabolic risk factors of chronic diseases collaborating group (Blood Glucose. National, regional, and global trends in fasting plasma glucose and diabetes prevalence since 1980: systematic analysis of health examination surveys and epidemiological studies with 370 country-years and 2.7 million participants. The Lancet. 378, 31-40.

De, B., Deb, S.R., Chakraborty, S., Namasudra, U., Pal, M.R., Choudhury, R., Goswami, B.B., Datta, S.P., Sen, S. and Chakraborty, R. 2012. Antibacterial and antidiabetic evaluation of bile content of Catla catla and Labeo rohita. Central Eur. J. Exp. Biol. 1, 107112.
Guariguata, L., Whiting, D.R., Hambleton, I., Beagley, J., Linnenkamp, U. and Shaw, J.E. 2014. Global estimates of diabetes prevalence for 2013 and projections for 2035. Diabetes Res. Clin. Pract. 103, 137-149.

Guyton and Hall. 2011. Textbook of Medical Physiology. U.S.: Saunders Elsevier. ISBN 978-1-4160-4574-8. p. 784.

Han Cho, N. 2014. International Diabetes Federation (IDF). IDF Diabetes Atlas, $6^{\text {th }}$ edn. International Diabetes Federation, Brussels, Belgium.

Hofmann, A.F., Hagey, L.R. and Krasowski, M.D. 2010. Bile salts of vertebrates: structural variation and possible evolutionary significance $[\mathrm{S}]$. J. Lipid Res. 51, 226-246.

International Diabetes Federation (IDF) [Internet]. Country estimates table 2011. IDF diabetes atlas. $6^{\text {th }}$ edn. 2012. (last accessed: 7 June 2013).

Lim, S.S., Vos, T., Flaxman, A.D., Danaei, G., Shibuya, K., Adair-Rohani, H., AlMazroa, M.A., Amann, M., Anderson, H.R., Andrews, K.G. and Aryee, M., 2012. A comparative risk assessment of burden of disease and injury attributable to 67 risk factors and risk factor clusters in 21 regions, 1990-2010: a systematic analysis for the global burden of disease study 2010. The Lancet. 380, 2224-2260.

Mendis, S., Puska, P., Norrving, B. and World Health Organization. 2011. Global atlas on cardiovascular disease prevention and control. World Health Organization.

Mitra, A. 2008. Some salient points in dietary and life-style survey of rural Bengal particularly tribal populace in relation to rural diabetes prevalence. Stud. EthnoMed. 2. 51-56.

Prawitt J., Caron, S. and Staels, B. 2011. Bile acid metabolism and the pathogenesis of type 2 diabetes. Curr. Diab. Rep. 11, 160-166.

Saquib, N., Saquib, J., Ahmed, T., Khanam, M.A. and Cullen, M.R. 2012. Cardiovascular diseases and type 2 diabetes in Bangladesh: a systematic review and metaanalysis of studies between 1995 and 2010. BMC Public Health. 12, 1-10.

Supriya, M., Sachin, S., Sharma, N.K. and Dharmendra, S. 2010. Hypoglycemic effect of Holarrhena antidysenterica seeds on streptozotocin induced diabetic rats. Int. J. Pharm. Tech. Res. 2, 1325-1329. 